\title{
Visible Photoluminescence Components of Solution-Grown ZnO Nanowires: Influence of the Surface Depletion Layer
}

\author{
Jiandong Fan, ${ }^{\dagger}$ Frank Güell, ${ }^{\dagger}$ Cristian Fábrega, ${ }^{\ddagger}$ Andrew Fairbrother, ${ }^{\ddagger}$ Teresa Andreu, ${ }^{\ddagger}$ \\ Antonio M. López, ${ }^{\S}$ Joan Ramón Morante, ${ }^{\dagger, \$}$ and Andreu Cabot ${ }^{*}, \dagger,+$ \\ ${ }^{\dagger}$ Departament Electronica, Universitat de Barcelona, Barcelona 08028, Spain \\ ${ }^{\ddagger}$ Catalonia Institute for Energy Research, IREC, Sant Adria del Besos, Barcelona 08930, Spain \\ ${ }^{\S}$ Departament d'Enginyeria Electrónica, Universitat Politècnica de Catalunya, EPSEVG, Avinguda Victor Balaguer s/n, 08800 \\ Barcelona, Spain
}

\section{Supporting Information}

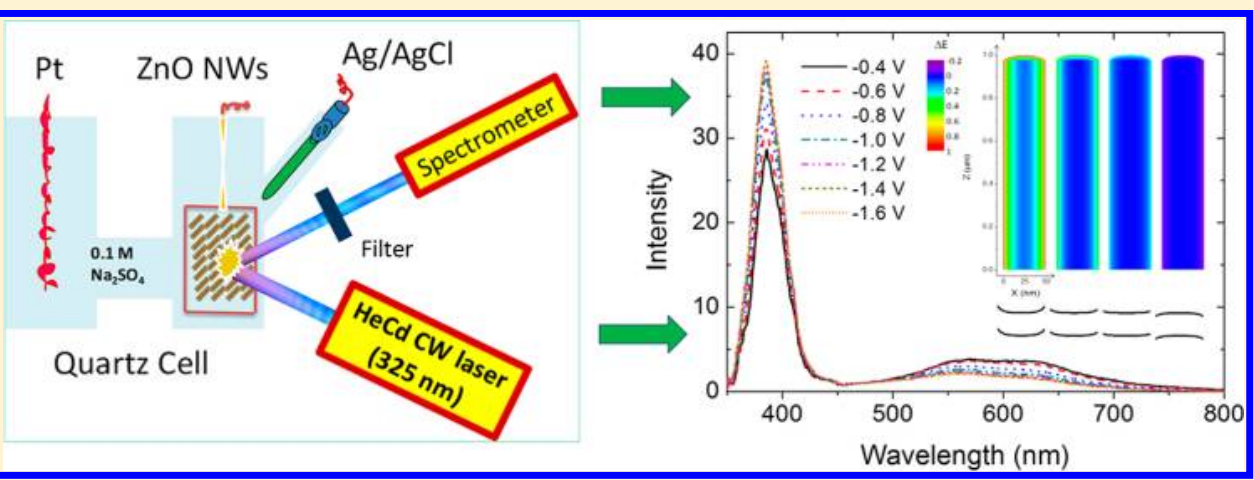

ABSTRACT: Arrays of electrodeposited $\mathrm{ZnO}$ nanowires (NWs) were used to illustrate the dependence of the $\mathrm{ZnO}$ visible photoluminescence (PL) emission on the extension of the surface depletion layer and obtain further insight into the localization of the related states. With this goal in mind, three sets of measurements were carried out: (i) analysis of the PL spectra of $\mathrm{ZnO}: \mathrm{Cl}$ NWs as a function of their carrier concentration; (ii) analysis of the PL spectra of $\mathrm{ZnO}: \mathrm{Cl} / \mathrm{ZnO}$ core-shell NWs as a function of the thickness of their intrinsic $\mathrm{ZnO}$ shell; (iii) in situ analysis of the $\mathrm{PL}$ dependence on the polarization of $\mathrm{ZnO}: \mathrm{Cl}$ photoelectrodes. The obtained experimental results evidenced that the yellow and orange emissions from electrodeposited $\mathrm{ZnO}$ NWs are correlated with the extension of the NWs surface depletion region. This result points out the surface localization of the states at the origin of these transitions. On the other hand, the green emission that dominates the visible part of the PL spectra in annealed $\mathrm{ZnO}$ NWs showed no dependence on the surface band bending, thus pointing toward its origin in the bulk.

\section{INTRODUCTION}

Zinc oxide, having a wide direct band gap $(3.37 \mathrm{eV})$ and large exciton binding energy $(60 \mathrm{meV})$, is an excellent candidate for optoelectronic applications, such as light-emitting diodes, ${ }^{1}$ laser diodes $^{2}$ and solar cells. ${ }^{3}$ Its wide range of applications has motivated a comprehensive characterization of its properties and an intensive investigation of its potential applications. Nevertheless, a lack of consensus on important optical properties, such as the origin of its visible photoluminescence (PL) emission, still exists. ${ }^{4-6}$ The various contributions to the visible emission has been associated with oxygen vacancies, ${ }^{7-14}$ oxygen antisites, oxygen interstitial, ${ }^{15,16}$ zinc vacancy, ${ }^{17-20}$ zinc interstitials, ${ }^{21,22}$ trapped $\mathrm{OH}^{-}$groups, ${ }^{18}$ and even $\mathrm{Cu}$ impurities. $^{23}$ On the other hand, evidence exists that the intensity of some contributions to the visible emission band depends on the material surface-to-bulk ratio. ${ }^{24-29}$ Such experimental evidence has been rationalized by considering the surface localization of the related states, their surface activation by the hole accumulation at the surface depletion region, or the promotion of slower recombination processes by charge separation in the built-in electric field surface layer. ${ }^{9-12,30-36}$ The surface band bending has also been reported to activate indirect band-to-band transitions. ${ }^{37}$

The controversy about the association of the transitions behind the visible PL emission is in part originated from the strong dependence of the PL emission on the $\mathrm{ZnO}$ preparation techniques, the specific growth parameters used, and the applied postgrowth treatments. ${ }^{38}$ The large variety of methods available for the synthesis of $\mathrm{ZnO}$ crystals with different geometries and sizes does not help to solve this puzzle. In this scenario, a particularly interesting geometry at the nanometer scale is that of nanowires (NWs). ${ }^{4,39,40}$ Its interest originates from the potential concurrence of a high electrical conductivity and a high surface area in the same structure. $\mathrm{ZnO}$ NWs can be

Received: March 13, 2012

Revised: August 14, 2012

Published: August 15, 2012 


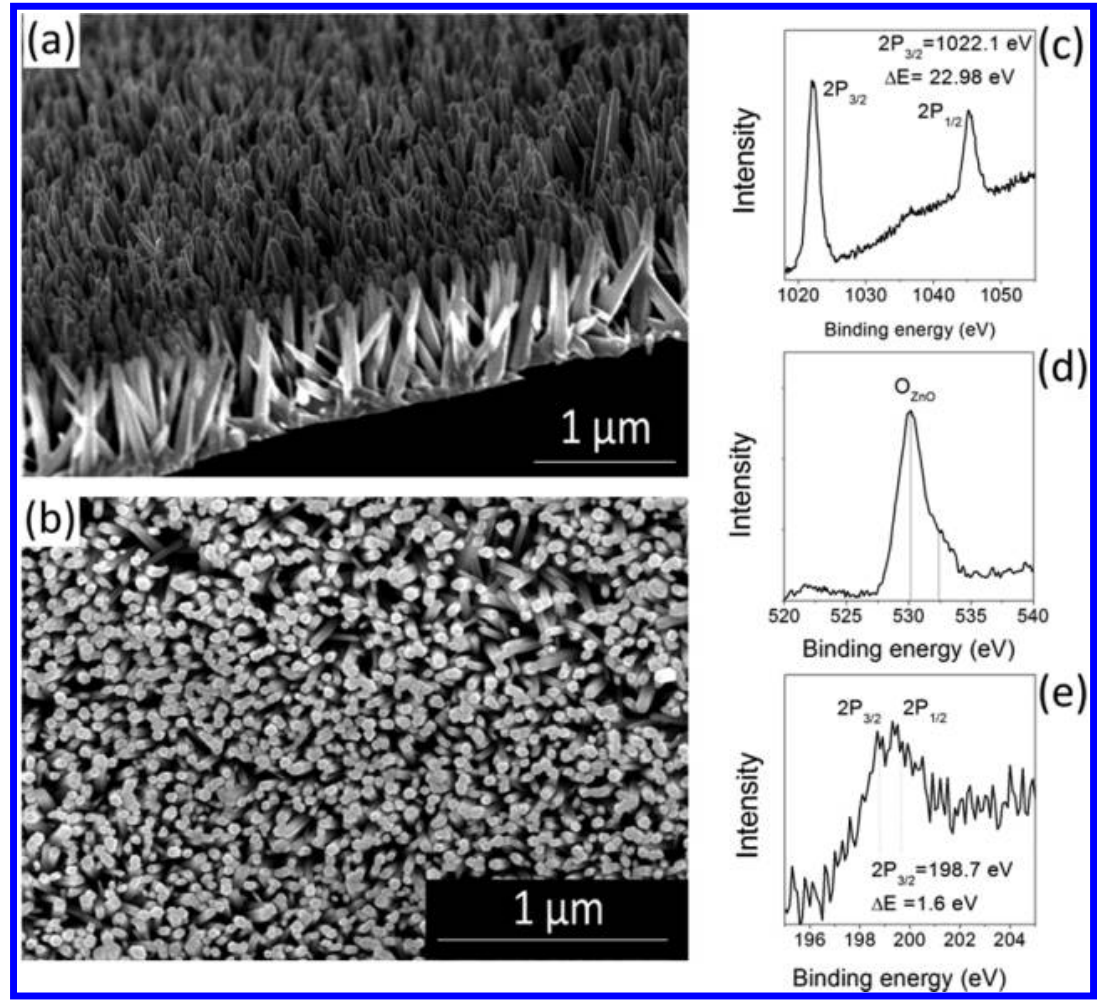

Figure 1. (a) Cross-sectional and (b) top-down SEM images of $\mathrm{ZnO}: \mathrm{Cl}$ nanowires. (c) Zinc region, (d) oxygen region, and (e) chlorine region of the XPS spectra of $\mathrm{ZnO}: \mathrm{Cl}$ nanowires.

prepared by vapor-phase transport, ${ }^{41}$ pulsed laser deposition, ${ }^{42}$ or chemical vapor deposition. ${ }^{43}$ However, alternative solutiongrowth methods, such as chemical bath deposition ${ }^{44,45}$ and electrochemical deposition, ${ }^{46,47}$ are more suitable for the preparation of large areas of aligned NWs arrays with controlled doping concentrations, at low temperatures, and at high production rates and yields.

In this work, the PL properties of solution-grown $\mathrm{ZnO}$ NWs are characterized. In particular, the dependence of the UV and visible PL band intensities on the surface band bending is analyzed and detailed. Evidence of a strong dependence of the yellow and orange emission on the extension of the surface depletion layer is revealed and discussed.

\section{EXPERIMENTAL SECTION}

NWs Growth. ZnO NWs were electrochemically grown in an aqueous solution inside a three-electrode cell. The growth solution was prepared by incorporating $10 \mathrm{~mL}$ of a $0.1 \mathrm{M}$ aqueous solution (Milli-Q+, $18.2 \mathrm{M} \Omega \cdot \mathrm{cm}$ ) of zinc nitrate $\left(\mathrm{Zn}\left(\mathrm{NO}_{3}\right)_{2} \cdot 4 \mathrm{H}_{2} \mathrm{O}\right)$ and $10 \mathrm{~mL}$ of a $0.1 \mathrm{M}$ aqueous solution of methenamine $\left(\mathrm{C}_{6} \mathrm{H}_{12} \mathrm{~N}_{4}\right)$ in $80 \mathrm{~mL}$ of deionized water and quickly heating up the solution to $90{ }^{\circ} \mathrm{C}$ on a hot plate. A platinum wire immersed in the solution was used as a counter electrode. $\mathrm{An} \mathrm{Ag} / \mathrm{AgCl}$ electrode in saturated $\mathrm{KCl}(3 \mathrm{M})$ was used as the reference electrode. A negative dc potential in the range between -0.4 and $-1.4 \mathrm{~V}$ relative to the reference electrode was applied to a soda-lime glass substrate coated with fluorine-doped tin oxide (FTO), indium-doped tin oxide (ITO), or Pt, which was used as a substrate for the $\mathrm{ZnO}$ NWs growth. After $1 \mathrm{~h}$ of growth time, the samples were immediately rinsed with deionized water. Chlorine ions were introduced in a controlled manner by replacing part of the deionized water with a $1 \mathrm{M}$ aqueous solution of ammonium chloride $\left(\mathrm{NH}_{4} \mathrm{Cl}\right)$. To obtain the coaxial $\mathrm{ZnO}: \mathrm{Cl} / \mathrm{ZnO}$ homojunction $\mathrm{NWs}$, the initial $\mathrm{ZnO}: \mathrm{Cl} \mathrm{NWs}$ were thoroughly washed and subsequently subjected to additional electrodeposition growth steps in the absence of $\mathrm{NH}_{4} \mathrm{Cl}$. The applied potential was fixed at $-0.4 \mathrm{~V}$ vs $\mathrm{Ag} / \mathrm{AgCl}$. The thickness of the $\mathrm{ZnO}$ shell could be controlled by the electrodeposition time (300 s) and/or the number (1-5) of additional electrodeposition growth steps.

Characterization. Field emission scanning electron microscopy (SEM) was used to characterize the morphology of the obtained materials and measure the density of NWs and their length and width distributions. Both cross-sectional and topdown views were obtained using a FEI Nova Nanosem 230. Xray photoelectron spectroscopy (XPS) spectra were obtained using a SPECS SAGE ESCA system employing $\mathrm{Mg} \mathrm{K} \alpha(E=$ $1253.6 \mathrm{eV}$ ) with a supplied power of $203 \mathrm{~W}$ as the X-ray source. The general spectra were scanned to confirm the presence of $\mathrm{Zn}, \mathrm{O}$, and $\mathrm{Cl}$ with $30 \mathrm{eV}$ pass energy and $0.5 \mathrm{eV}$ steps. Highresolution scans were obtained to provide information regarding the bonding environment and oxidation states of $\mathrm{Zn}, \mathrm{O}$, and $\mathrm{Cl}$. These scans were performed with $15 \mathrm{eV}$ pass energy and $0.10 \mathrm{eV}$ steps. All spectra were shifted to account for sample charging using carbon at $284.80 \mathrm{eV}$ as a reference. Room-temperature PL measurements were obtained using a Kimmon IK Series HeCd CW laser (325 nm and $40 \mathrm{~mW}$ ). Light was dispersed through an Oriel Corner Stone 1/8 74000 monochromator, detected with a Hamamatsu R928 photomultiplier, and amplified through a Stanford Research Systems SR830 DSP lock-in amplifier. The dependence of the PL intensity on an external applied field was measured by introducing the NWs inside a quartz electrochemical cell. Potential was applied using a three-electrode potentiostat system with an $\mathrm{Ag} / \mathrm{AgCl}$ electrode in saturated $\mathrm{KCl}(3 \mathrm{M})$ as 


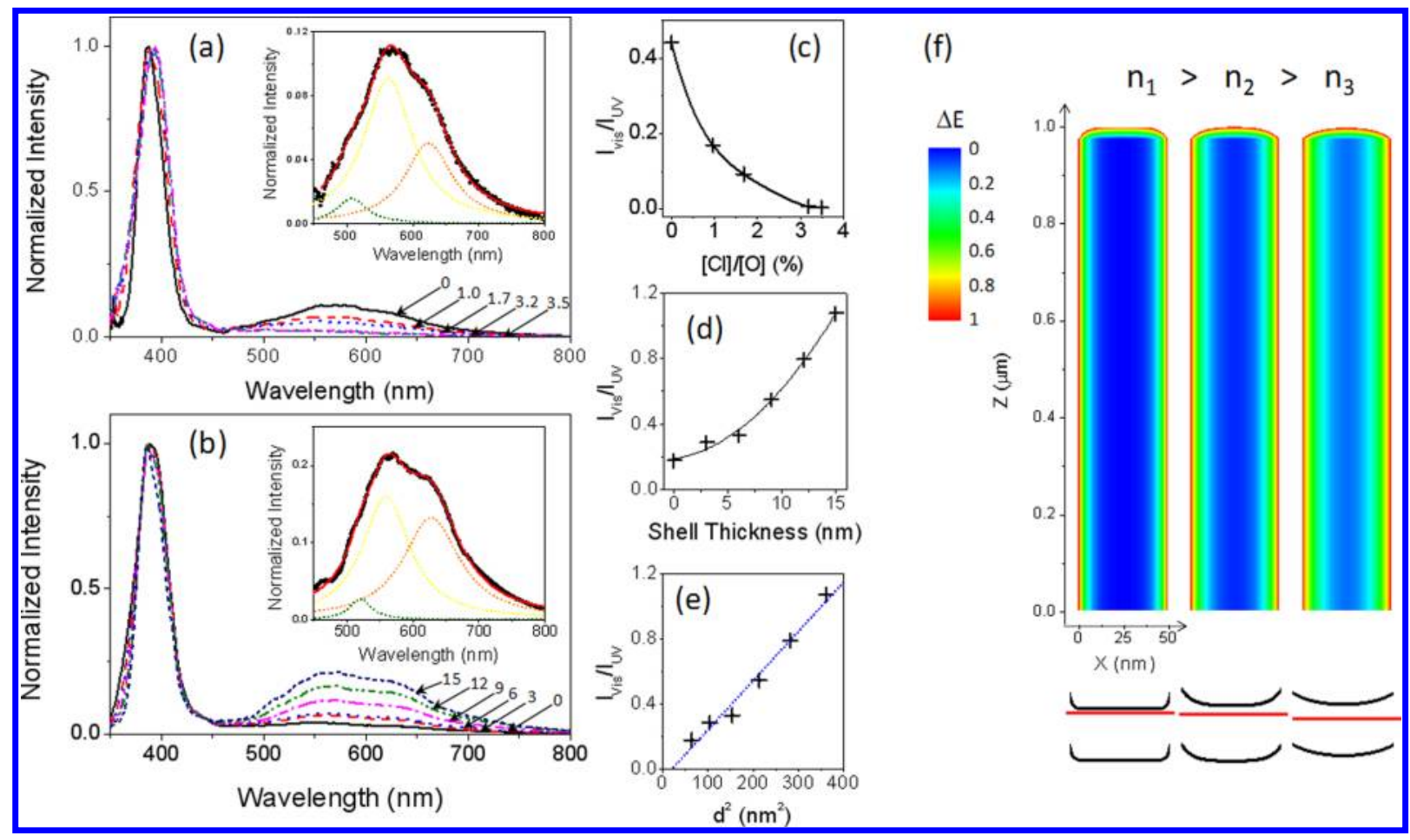

Figure 2. (a) Room-temperature photoluminescence spectra of $\mathrm{ZnO}: \mathrm{Cl}$ nanowires with different $\mathrm{Cl}$ concentrations. The ratios $[\mathrm{Cl}] /[\mathrm{O}]$, as measured by XPS, were 0, 1.0, 1.7, 3.2 and 3.5\%. Inset shows the visible emission in more detail and the fitting of the different emission bands. (b) Room-temperature photoluminescence spectra of $\mathrm{ZnO}: \mathrm{Cl}$ nanowires and $\mathrm{ZnO}: \mathrm{Cl} / \mathrm{ZnO}$ homojunction nanowires with increasingly thicker shells: 0 , 3, 6, 9, 12, and $15 \mathrm{~nm}$. (c) Chlorine dependence of the PL intensity ratio between the UV and visible bands. (d) Shell-thickness dependence of the PL intensity ratio between the UV and visible bands. (e) Dependence of the UV-vis emission intensity ratio on the square of the estimated depletion layer thickness. (f) Schematic view of the energy levels variation across nanowires with different carrier concentrations.

the reference electrode and a Pt wire as counter electrode. A 0.1 $\mathrm{M} \mathrm{Na} \mathrm{SO}_{4}$ aqueous solution was used as electrolyte.

\section{RESULTS AND DISCUSSION}

Parts a and b of Figure 1 show representative top-down and cross-sectional SEM images of an array of vertically aligned and single-crystal $\mathrm{ZnO}: \mathrm{Cl} \mathrm{NWs}$ grown by electrodeposition along the $\langle 0001\rangle$ direction. The $\mathrm{ZnO}: \mathrm{Cl} \mathrm{NWs}$ had an average diameter of $170 \mathrm{~nm}$ and an average length of $2.3 \mu \mathrm{m}$. A controlled concentration of chlorine ions was introduced by dissolving the required amount of ammonium chloride inside the electrodeposition solution. The concentration and chemical state of chlorine ions within the $\mathrm{ZnO}$ structure were analyzed by XPS (Figure $1 \mathrm{c}-\mathrm{e}$ ). Chlorine ions are well-known to act as n-type impurities within the $\mathrm{ZnO}$ structure. Thus controlling the amount of chlorine, the $\mathrm{ZnO}: \mathrm{Cl}$ charge carrier concentration could be adjusted in the range from $10^{17}$ to $10^{20} \mathrm{~cm}^{-3} \cdot 47$

The room-temperature PL spectra of $\mathrm{ZnO}: \mathrm{Cl} \mathrm{NWs} \mathrm{having}$ different doping concentrations are shown in Figure 2a. A strong UV peak, associated with the band-to-band recombination, is clearly seen at $390 \mathrm{~nm}$. The slight red shift of the UV emission peak with the $\mathrm{Cl}$ doping concentration may be related to a small band gap narrowing associated with the high density of charge carriers introduced in the $\mathrm{ZnO}$ crystal structure or to the preponderance in the PL emission spectra of $\mathrm{ZnO}: \mathrm{Cl} \mathrm{NWs}$ of an exciton slightly below the conduction band edge. ${ }^{47,48} \mathrm{~A}$ broad emission band in the visible part of the spectra is also observed. The visible band has at least two contributions centered at approximately $570 \mathrm{~nm}$ (yellow) and $620 \mathrm{~nm}$ (orange). A third band, centered at $510 \mathrm{~nm}$ (green), could be also fitted (Figure 2a). Similar bands are commonly observed in solution-processed $\mathrm{ZnO}$ nanoparticles and nanowires. ${ }^{18,33}$ Our experimental results show that when increasing the doping concentration, the relative intensity of the broad visible band decreases with respect to the UV emission band (Figure 2a and c). The doping concentration affected the two main visible contributions, yellow and orange, in a similar way. However, the intensity of the potential green band was not influenced by the doping concentration.

In Figure $2 \mathrm{~b}$, the room-temperature $\mathrm{PL}$ spectra of $\mathrm{ZnO}: \mathrm{Cl} /$ $\mathrm{ZnO}$ core-shell NWs having different shell thicknesses are plotted. These homojunction $\mathrm{ZnO}: \mathrm{Cl} / \mathrm{ZnO}$ NWs were produced by a two-step electrodeposition process. The $[\mathrm{Cl}] /$ [O] ratio of the $\mathrm{ZnO}: \mathrm{Cl}$ core measured by XPS was $3.2 \%$. The $\mathrm{PL}$ spectra obtained from these NW arrays was very similar to those measured from $\mathrm{ZnO}: \mathrm{Cl} \mathrm{NWs}$. However, in this case, the relative intensity of the visible band increased with the thickness of the intrinsic $\mathrm{ZnO}$ shell (Figure $2 \mathrm{~b}$ and $\mathrm{d}$ ). This increase was correlated with the thickness of the calculated surface depletion layer (Figure 2e). Again, the shell thickness seems to affect the two main visible contributions, yellow and orange, in the same direction.

Both experimental observations can be explained using the same model. It is well-known that the electrical and optical properties of wide band gap oxide semiconductors are highly susceptible to the surrounding gas atmosphere. In ambient conditions, the surface of $\mathrm{ZnO} \mathrm{NWs}$ is covered by ionized oxygen species and hydroxyl groups that trap conduction band electrons. This negative surface charge distribution causes an upward bending of the $\mathrm{ZnO}$ energy bands at the surface. The surface barrier height depends on the relative position of the chemisorbed species energy levels with respect to the $\mathrm{ZnO}$ 
Fermi level. On the other hand, the width of the depletion layer is strongly dependent on the doping concentration and can be estimated by solving the Poisson equation

$$
d=\left[\frac{2 \varepsilon \varepsilon_{0} \Phi_{s}}{e^{2} N_{\mathrm{D}}}\right]^{1 / 2}
$$

where $\varepsilon$ is the $\mathrm{ZnO}$ relative dielectric constant (8.7), $\varepsilon_{0}$ is the vacuum permittivity, $\Phi_{\mathrm{s}}$ is the height of potential barrier, $e$ is the electron charge, and $N_{\mathrm{D}}$ is the donor concentration. For $\mathrm{ZnO}$ in ambient atmosphere, the barrier height is typically close to $0.55 \mathrm{eV} .{ }^{17}$ While highly conducting $\mathrm{ZnO}: \mathrm{Cl}$ NWs are able to screen the surface charge within a very thin surface depletion layer, undoped $\mathrm{ZnO} \mathrm{NWs}$ are characterized by much thicker depletion regions. In this regard, the width of the depletion layer is calculated to be $70 \mathrm{~nm}$ for $\mathrm{ZnO}$ with a donor concentration of $10^{17} \mathrm{~cm}^{-3}$ and less than $2 \mathrm{~nm}$ for a carrier concentration of $10^{20} \mathrm{~cm}^{-3} \cdot 10,49-52$

As illustrated in Figure 2c, the variation of the relative visible PL band intensity with the doping concentration correlates well with the reduction of the estimated thickness of the surface depletion layer required to screen the surface charge. At the same time, in core-shell nanowires, the presence of an undoped $\mathrm{ZnO}$ shell on the surface of highly doped $\mathrm{ZnO}: \mathrm{Cl}$ NWs allowed increasing the thickness of the depletion layer while conserving a highly conductive core. The visible PL band increased with the thickness of the surface depletion layer (Figure $2 \mathrm{~d}$ and e). These two evidences were indirect demonstrations that the yellow and orange PL bands obtained from solution-grown $\mathrm{ZnO} \mathrm{NWs}$ had their origin at the $\mathrm{NW}$ surface.

To obtain direct evidence of the influence of the surface depletion layer on the relative intensity of the visible band and discard the influence of other chemical, structural, or geometrical parameters, the $\mathrm{PL}$ properties of $\mathrm{ZnO}: \mathrm{Cl} \mathrm{NWs}$ were characterized while adjusting their surface band bending by means of an applied potential. ${ }^{53-55}$ For this purpose, the $\mathrm{ZnO}: \mathrm{Cl} \mathrm{NWs}$ were immersed inside a quartz electrochemical cell filled with a $0.1 \mathrm{M} \mathrm{Na}_{2} \mathrm{SO}_{4}$ aqueous solution as electrolyte. A potential was applied using a three-electrode potentiostat system with an $\mathrm{Ag} / \mathrm{AgCl}$ electrode in saturated $\mathrm{KCl}(3 \mathrm{M})$ as the reference electrode and a $\mathrm{Pt}$ wire as counter electrode (Figure 3). When immersing a semiconductor electrode in a

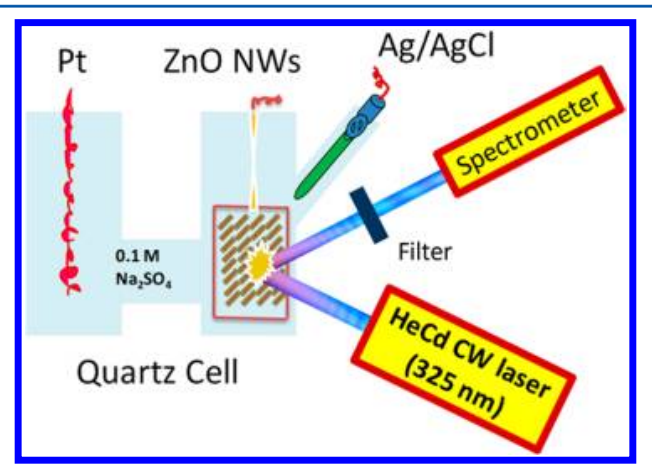

Figure 3. Schematic illustration of the setup used to measure the photoluminescence spectra of $\mathrm{ZnO}: \mathrm{Cl}$ nanowires under polarization. $\mathrm{ZnO}: \mathrm{Cl}$ nanowires were immersed in a $0.1 \mathrm{M} \mathrm{Na}_{2} \mathrm{SO}_{4}$ aqueous solution inside a quartz electrochemical cell. A potential was applied to the $\mathrm{ZnO}: \mathrm{Cl}$ nanowire-based photoelectrodes using a three-electrode potentiostat system with an $\mathrm{Ag} / \mathrm{AgCl}$ electrode in saturated $\mathrm{KCl}(3 \mathrm{M})$ as the reference electrode and a Pt wire as counter electrode. redox electrolyte, a gradient of electrochemical potential across the interface exists. The polarization of the $\mathrm{ZnO}: \mathrm{Cl} \mathrm{NWs}$ immersed in the electrolyte shifts the energy bands upward/ downward in the NW core, altering in this way the surface band bending, as illustrated in Figure $4 \mathrm{~b}$ and $\mathrm{c}$. In these conditions, a controllable gradient of electrochemical potential across the interface can be created.

Positive potentials shift the energy levels of the NW core downward, thus increasing the potential barrier between the core and the pinned surface states. In these conditions, the anodic current associated with the injection of photogenerated holes from the semiconducting electrode to the electrolyte is extremely small in the dark (Figure 4a). This is because of the lack of holes in the n-type $\mathrm{ZnO}: \mathrm{Cl}$ electrode. If holes are photogenerated within the $\mathrm{ZnO}: \mathrm{Cl}$ electrode, an anodic photocurrent is measured at all anodic potentials. As illustrated in Figure $4 b$, positive potentials facilitate the separation of electron-hole pairs by extending the charge depletion layer where a build-in electric field drives holes toward the electrolyte and electrodes toward the substrate through the $\mathrm{ZnO}: \mathrm{Cl} \mathrm{NW}$ core. Thus the measured photocurrent increases with the positive applied potential, until reaching a saturation photocurrent that depends on the illumination intensity. ${ }^{56}$

Negative applied voltages shift up the energy bands at the NW core, reducing in this way the surface band bending. Such a decrease of the surface depletion layer results in a reduction of the measured photocurrents. At sufficiently high negative polarizations, negative currents are measured, corresponding to the injection of electrons from the semiconductor to the electrolyte (Figure 4c).

Figure 5 shows the room-temperature PL spectra at different applied potentials of a $\mathrm{ZnO}: \mathrm{Cl} \mathrm{NW}$ array immersed inside the electrochemical cell. At positive applied potential, the intensity of both UV and visible bands significantly decreased (Figure 5c). There is an obvious competition between the radiative recombination of electron-hole pairs photogenerated upon UV illumination and the extraction of minority carriers (Figure $4 b$ ). This competition could explain a reversible quenching of PL when increasing the positive applied voltage. However, the PL quenching with the positive potential was not reversible. A visual examination of the layer after PL characterization at positive applied voltages revealed the decomposition of the $\mathrm{ZnO}$ NWs. A detailed SEM exploration of the area exposed to the UV light revealed that $\mathrm{ZnO}$ NWs had been mostly dissolved with the relatively high photocurrents generated by the combination of the strong UV laser radiation and the positive applied potential (Supporting Information Figure S1). ${ }^{57}$ At the edge of the UV-exposed area, $\mathrm{ZnO}$ nanotubes were observed. The conservation of the $\mathrm{ZnO} \mathrm{NWs}$ in the nonexposed area demonstrated that the UV exposure was necessary to dissolve the $\mathrm{ZnO}$ nanowires. The $\mathrm{ZnO}$ spectroelectrochemical dissolution could result from a reverse electrosynthesis reaction at positive potentials under UV illumination. Similar photoelectrochemical dissolution reactions have been previously repoted. ${ }^{55}$

On the other hand, when changing the applied potential toward negative values, the intensity of the visible band clearly decreased. At the same time, the UV emission peak intensity evidently increased (Figure 5a, b). The variation of the visible band intensity affected both yellow and orange contributions in a similar way. It is worth noting that the PL spectra evolution with the applied voltage was reversible, allowing the recovery of the initial spectra when reducing the applied negative voltage. 


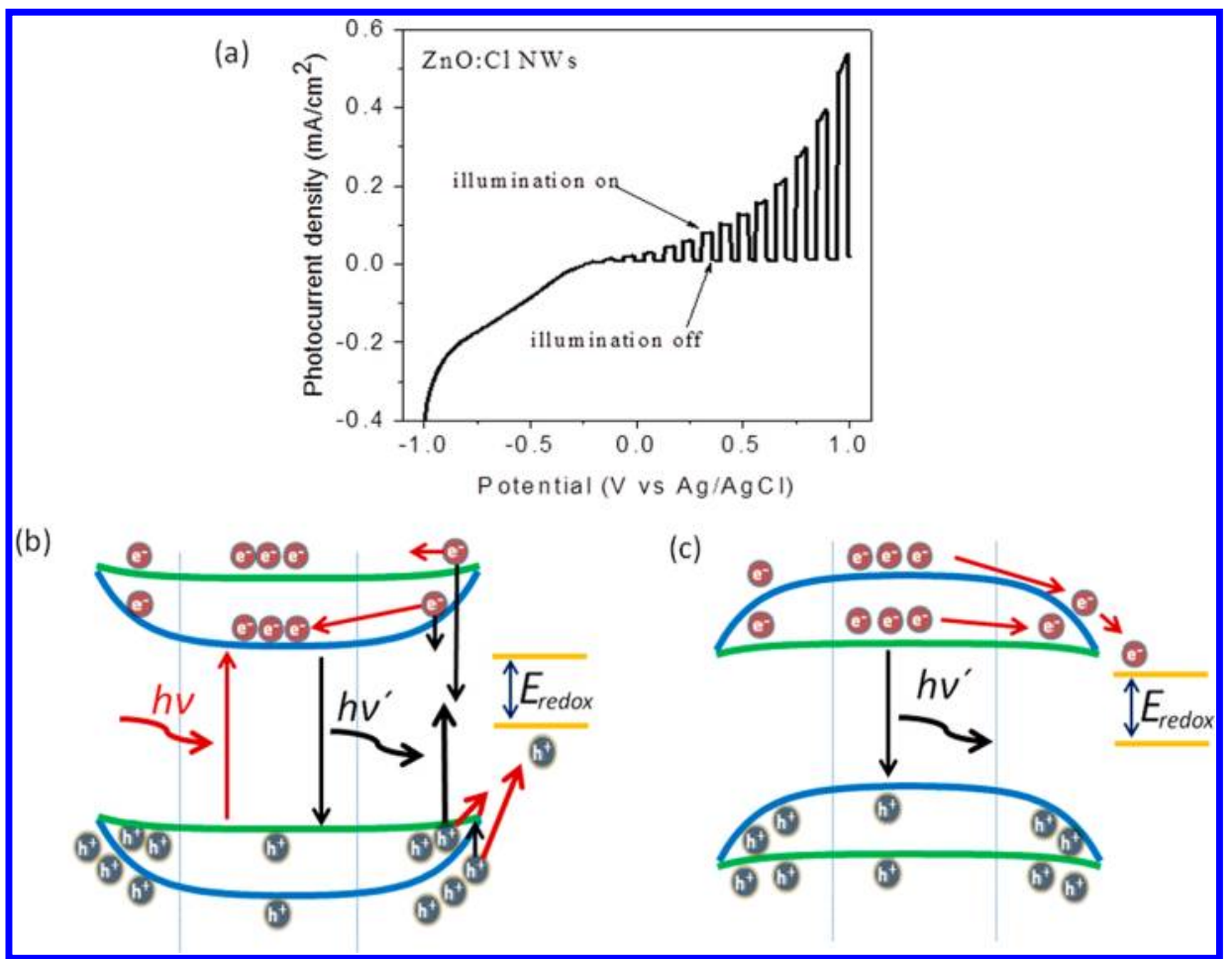

Figure 4. (a) Photocurrent density vs applied potential ( $\mathrm{V}$ vs $\mathrm{Ag} / \mathrm{AgCl}$ ) for $\mathrm{ZnO}: \mathrm{Cl} \mathrm{NWs}$ measured under chopped UV illumination in a $0.1 \mathrm{M}$ $\mathrm{Na}_{2} \mathrm{SO}_{4}$ aqueous solution. (b) Representation of the effects of band bending on the competing evolution of electron-hole separation (red arrow) and recombination (black arrow) process at positive applied potential. (c) Representation of the effects of band bending on the electrochemical photoluminescence induced by electron-hole recombination at negative applied potential. Intraband gap states were omitted for simplicity.
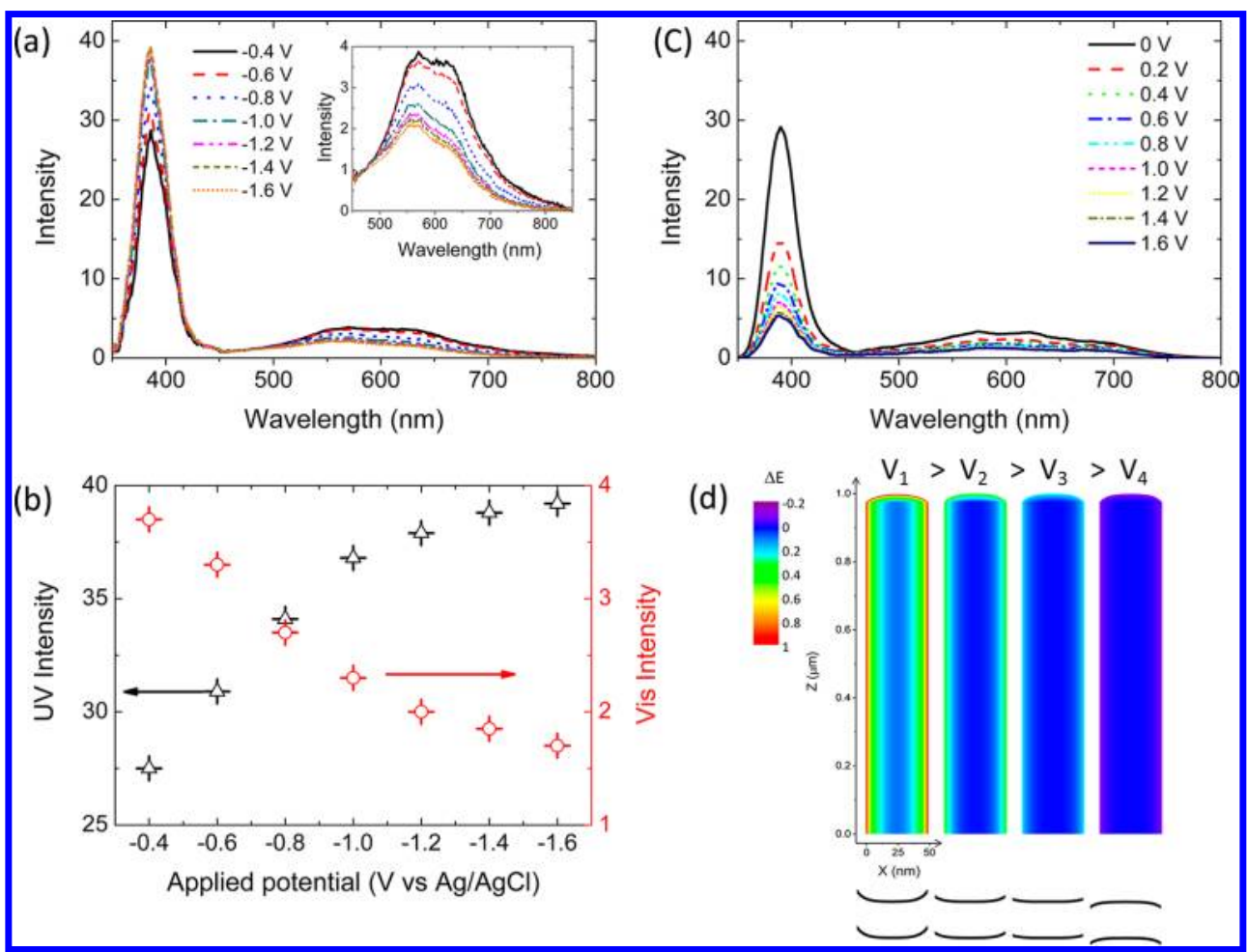

Figure 5. (a) Room-temperature photoluminescence spectra of $\mathrm{ZnO}: \mathrm{Cl}$ nanowires at different negative potential. Inset shows the visible emission in more detail. (b) Evolution of UV and visible emission intensities with the applied potential. (c) Room-temperature photoluminescence spectra of $\mathrm{ZnO}: \mathrm{Cl}$ nanowires at positive potentials. (d) Schematic view of the energy level variation across nanowires polarized at different potentials.

These results evidence that orange and yellow PL bands obtained from solution-grown $\mathrm{ZnO} \mathrm{NWs}$ were strongly dependent on the surface band bending. Yellow and orange emissions were previously associated with transitions from the conduction band, donor $\mathrm{OH}^{-}$states, or zinc interstitials to oxygen interstitials or zinc vacancies. ${ }^{18,33,58}$ The results 
reported here do not allow determination of the specific chemical identity of the trap state, but evidence their surface localization. The electric field inside the depletion layer helps to separate photogenerated electron-hole pairs, driving electrons to the bulk and holes to the surface. The contribution from states localized directly at the $\mathrm{ZnO}$ surface would increase with the extension of the surface depletion layer because of the higher amount of holes harvested. On the other hand, hole accumulation at the depletion layer, localized either in the valence band or in defect states, such as ionized oxide vacancies, could also activate radiative states not active within the nanocrystal bulk. A third possibility is the slowdown of bandto-band transitions at the depletion region due to the existence of a driving force for exciton separation. In this scenario, slower radiative recombination processes with much lower efficiencies in the $\mathrm{ZnO}$ bulk would be promoted at the $\mathrm{ZnO}$ surface (Figure 6a).

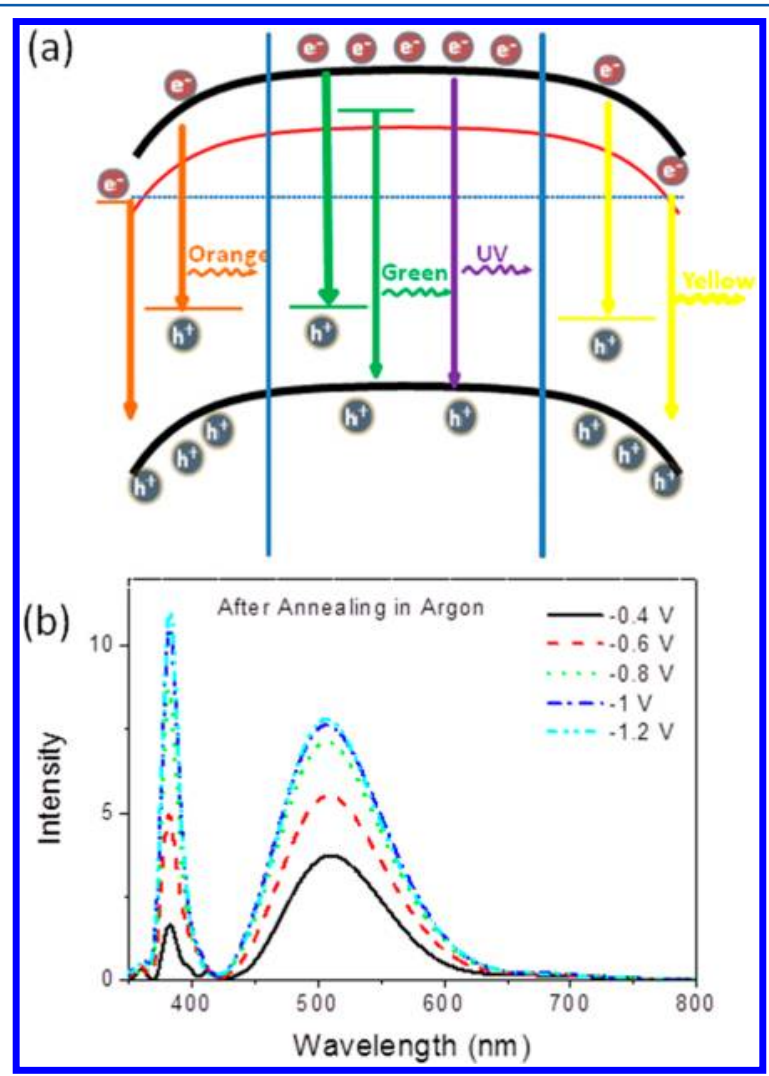

Figure 6. (a) Schematic of the possible localization of the states contributing to the visible emission within $\mathrm{ZnO}$ nanowires. (b) Roomtemperature photoluminescence spectra of annealed $\mathrm{ZnO}: \mathrm{Cl}$ nanowires at increasingly higher negative potentials.

Finally, the $\mathrm{ZnO} \mathrm{NW}$ arrays obtained by electrodeposition were annealed in argon at $450{ }^{\circ} \mathrm{C}$ during $1 \mathrm{~h}$. The morphology and composition of $\mathrm{ZnO}: \mathrm{Cl} \mathrm{NWs}$ before and after annealing were analyzed using the exact same sample (Supporting Information Figure S3). The $\mathrm{O} / \mathrm{Zn}$ atomic ratio was 1.76 before annealing and 1.62 after annealing, as measured by EDX. It should be pointed out that the measured $\mathrm{O} / \mathrm{Zn}$ atomic ratios were influenced by the ITO-covered glass substrate. However, results obtained from the exact same sample before and after annealing clearly pointed out toward a decrease of the oxygen concentration with the annealing treatment in argon. This decrease could be attributed to the decomposition of $\mathrm{Zn}(\mathrm{OH})_{2}$ to $\mathrm{ZnO}$ and/or the desorption of chemisorbed oxygen or hydroxyl groups from the $\mathrm{ZnO}$ NWs surface with the annealing process.

The annealing treatment substantially modified the PL spectra. Figure $6 \mathrm{~b}$ shows the room-temperature PL spectra obtained from the annealed NWs. The UV peak corresponding to band-to-band recombination and a relatively broad visible band could be easily identified. The intensity of both bands clearly increased with the annealing process mainly due to the improvement of the crystalline structure and the removal of nonradiative defects (Supporting Information Figure S2). At the same time, the relative intensity of the visible band increased considerably. However, in this case, the visible band showed only one contribution, centered at around $510 \mathrm{~nm}$ (green). Such emission at $510 \mathrm{~nm}$ has been previously associated with transitions involving oxygen vacancies and zinc interstitials. ${ }^{59}$

It is generally accepted that annealing in argon facilitates the removal of chemisorbed oxygen or other oxygen-containing species (e.g., $\mathrm{OH}^{-}$) from the $\mathrm{ZnO}$ surface, reducing the defect concentration and the charge depletion region and thus enhancing the UV emission. ${ }^{60}$ The decrease of the yellow and orange emission intensities with the annealing process is also consistent with the reduction of the defect concentration. In particular, the defects at the origin of these emissions are clearly eliminated with the annealing treatment. On the other hand, the relatively strong green emission obtained after the annealing process can be associated with the decrease of the oxygen concentration and the consequent increase of the concentration of oxygen vacancies and zinc interstitial defects with the annealing process in an inert atmosphere.

The PL spectra measured under electrical polarization showed that both the UV and green bands increased with the negative potential (Figure 6b). This general feature is in good agreement with an earlier report on electroluminescence spectroscopy of polycrystalline $\mathrm{ZnO}$ electrode and can be explained by the injection of minority carriers from the electrolyte to the semiconductor. ${ }^{61}$ These results point toward the bulk localization of the states at the origin of the green PL emission in annealed $\mathrm{ZnO} \mathrm{NWs}$ obtained by solutionprocessing methods. As in the case of as-grown $\mathrm{ZnO} \mathrm{NWs}$, the annealed arrays were not stable at positive potential when exposed to UV light.

\section{CONCLUSIONS}

Three sets of measurements were performed to demonstrate the strong dependence of the visible PL emission in solutiongrown $\mathrm{ZnO} \mathrm{NWs}$ on the thickness of the surface depletion region. The results obtained indicate that the orange and yellow emission bands originate from transitions taking place between states localized at or near the NW surface. On the other hand, the green emission measured from annealed $\mathrm{ZnO}$ NWs showed no dependence on the extension of the surface depletion layer and followed the same trend as the UV emission, which points toward its origin in the bulk.

\section{ASSOCIATED CONTENT}

\section{S Supporting Information}

$\mathrm{PL}$ spectrum of $\mathrm{ZnO}: \mathrm{Cl} \mathrm{NWs}$ before and after annealing at $0 \mathrm{~V}$, SEM images, and EDX results. This material is available free of charge via the Internet at http://pubs.acs.org. 


\section{AUTHOR INFORMATION}

\section{Corresponding Author}

*E-mail address acabot@irec.cat; tel. +34625615115.

Notes

The authors declare no competing financial interest.

\section{ACKNOWLEDGMENTS}

The research was supported by the European Regional Development Funds and by the Spanish MICINN projects MAT2008-05779, MAT2008-03400-E/MAT, MAT201015138, MAT2010-21510, CSD2009-00050, and ENE200803277-E/CON. J.F. is thankful for the FI-DGR grant from the Agència de Gestió d'Ajuts Universitaris i de Recerca (AGAUR) from the Catalan Government. A.C. is thankful for financial support through the Ramón y Cajal program to the Spanish MICINN.

\section{REFERENCES}

(1) Tsukazaki, A.; Ohtomo, A.; Onuma, T.; et al. Nat. Mater. 2005, 4, 42-46.

(2) Pauproté, T.; Lincot, D.; Viana, B.; Pellé, F. Appl. Phys. Lett. 2006, 89, 233112.

(3) Claude, L. C.; Ramon, T. Z.; Ryan, M. A. Adv. Mater. 2005, 17, $1512-1515$.

(4) Djurišić, A. B.; Leung, Y. H. Small 2006, 2, 944-961.

(5) Güell, F.; Ossó, J. O.; Goñi, A. R.; Cornet, A.; Morante, J. R. Superlattice. Microstruct. 2009, 45, 271-276.

(6) Güell, F.; Ossó, J. O.; Goñi, A. R.; Cornet, A.; Morante, J. R. Nanotechnology 2009, 20, 315701.

(7) Zheng, M. J.; Zhang, L. D.; Li, G. H.; Shen, W. Z. Chem. Phys. Lett. 2002, 363, 123-128.

(8) Vanheusden, K.; Seagera, C. H.; Warren, W. L.; Tallant, D. R.; Caruso, J.; Hampden-Smithb, M. J.; Kodasb, T. T. J. Lumin. 1997, 75, $11-16$.

(9) Vanheusden, K.; Warren, W. L.; Seager, C. H.; Tallant, D. R.; Voigt, J. A.; Gnade, B. E. J. Appl. Phys. 1996, 79, 7983-7990.

(10) Liao, Z. -M.; Zhang, H.-Z.; Zhou, Y.-B.; Xu, J.; Zhang, J.-M.; Yu, D.-P. Phys. Lett. A 2008, 372, 4505-4509.

(11) Bouzid, K.; Djelloul, A.; Bouzid, N.; Bougdira, J. Phys. Status Solidi A 2009, 206, 106-115.

(12) Vanheusden, K.; Seager, C. H.; Warren, W. L.; Tallant, D. R.; voigt, J. A. Appl. Phys. Lett. 1996, 68, 403-405.

(13) Ahn, M.-W.; Park, K.-S.; Heo, J.-H.; Park, J.-G.; Kim, D.-W.; Choi, K. J.; Lee, J.-H.; Hong, S.-H. Appl. Phys. Lett. 2008, 93, 263103.

(14) Van Dijiken, A.; Meulenkamp, E. A.; Vanmaekelberg, D.; Meijerink, A. J. Phys. Chem. B 2000, 104, 4355-4360.

(15) Fan, X. M.; Lian, J. S.; Jiang, Q.; Zhou, Z. W. J. Mater. Sci. 2007, $42,2678-2683$.

(16) Chang, S.-S. J. Korean Ceram. Soc. 2011, 48, 251-256.

(17) Lin, B.; Fu, Z.; Jia, Y. Appl. Phys. Lett. 2001, 79, 943-945.

(18) Manzano, C. V.; Alegre, D.; Caballero-Calero, O.; Alén, B.; Martín-González, M. S. J. Appl. Phys. 2011, 110, 043538.

(19) Janotti, A.; Van de Walle, C. G. Phys. Rev. B 2007, 76, 165202.

(20) Roro, K. T.; Dangbegnon, J. K.; Sivaraya, S.; Leitch, A. W. R.; Botha, J. R. J. Appl. Phys. 2008, 103, 053516.

(21) Liua, Z. W.; Ong, C. K.; Yu, T.; Shen, Z. X. Appl. Phys. Lett. 2006, 88, 053110 .

(22) Zeng, H.; Duan, G.; Li, Y.; Yang, S.; Xu, X.; Cai, W. Adv. Funct. Mater. 2010, 20, 561-572.

(23) Garces, N. Y.; Wang, L.; Bai, L.; Giles, N. C.; Halliburton, L. E.; Cantwell, G. Appl. Phys. Lett. 2002, 81, 622-624.

(24) Gu, X.; Huo, K.; Qian, G.; Fu, J.; Chu, P. K. Appl. Phys. Lett. 2008, 93, 203117.

(25) Andelman, T.; Gong, Y.; Polking, M.; Yin, M.; Kuskovsky, I.; Neumark, G.; O'Brien, S. J. Phys. Chem. B 2005, 109, 41314-14318. (26) Shalish, I.; Temkin, H.; Narayanamurti, V. Phys. Rev. B 2004, 69, 245401.
(27) Chang, P.-C.; Chien, C.-J.; Stichtenoth, D.; Ronning, C.; Lu, J. G. Appl. Phys. Lett. 2007, 90, 113101.

(28) Van Dijken, A.; Meulenkamp, E. A.; Vanmaekelbergh, D.; Meijerink, A. J. Phys. Chem. B 2000, 104, 1715-1723.

(29) Yousefi, R.; Kamaluddin, B. J. Alloys Compd. 2009, 479, 11-14.

(30) Wu, X. L.; Siu, G. G.; Fu, C. L.; Ong, H. C. Appl. Phys. Lett. 2001, 78, 2285-2287.

(31) Djurišić, A. B.; Leung, Y, H.; Choy, W. C. H.; Cheah, K. W.; Chan, W. K. Appl. Phys. Lett. 2004, 84, 2635-2637.

(32) Richters, J.-P.; Voss, T.; Kim, D. S.; Scholz, R; Zacharias, M. Nanotechnology 2008, 19, 305202.

(33) Shi, S.; Xu, J.; Zhang, X.; Li, L. J. Appl. Phys. 2011, 109, 103508.

(34) Ye, J. D.; Gu, S. L.; Qin, F.; et al. Appl. Phys. A: Mater. Sci. Process. 2005, 81, 759-762.

(35) Fan, J.; Guell, F.; Fabrega, C.; Shavel, A.; Carrete, A.; Andreu, T.; Morante, J. R.; Cabot, A. Appl. Phys. Lett. 2011, 99, 262102.

(36) House, R. L.; Mehl, B. P.; Kirschbrown, J. R.; barnes, S. C.; Papanikolas, J. M. J. Phys. Chem. C 2011, 115, 10806-10816.

(37) Yang, L. L.; Zhao, Q. X.; Israr, M. Q.; Sadaf, J. R.; Willander, M.; Pozina, G.; Yang, J. H. J. Appl. Phys. 2010, 108, 103513.

(38) Ahn, C. H.; Kim, Y. Y.; Kim, D. C.; Mohanta, S. K.; Cho, H. K. J. Appl. Phys. 2009, 105, 013502.

(39) Wang, Z. L. J. Phys.: Condens. Matter. 2004, 16, 829-858.

(40) Chu, D.; Masuda, Y.; Ohji, T.; Kato, K. J. Am. Ceram. Soc. 2010, 93, 887-893.

(41) Huang, M. H.; Wu, Y.; Feick, H.; Tran, N.; Weber, E.; Yang, P. Adv. Mater. 2001, 13, 113-116.

(42) Sun, Y.; Fuge, G. M.; Ashfold, M. N. R. Chem. Phys. Lett. 2004, 396, 21-26.

(43) Park, W. I.; Kim, D. H.; Jung, S. W.; Yi, G. C. Appl. Phys. Lett. 2002, 80, 4232-4234.

(44) Grene, L. E.; Yuhas, B. D.; Law, M.; Zitoun, D.; Yang, P. Inorg. Chem. 2006, 45, 7535-7543.

(45) Govender, K.; Boyle, D. S.; Kenway, P. B.; ÓBrien, P. J. Mater. Chem. 2004, 14, 2575-2591.

(46) Peulon, S.; Lincot, D. Adv. Mater. 1996, 8, 166-170.

(47) Fan, J.; Shavel, A.; Zamani, R.; Fábrega, C.; et al. Acta Mater. 2011, 59, 6790-6800.

(48) Egelhaaf, H.-J; Oelkrug, D. J. Cryst. Growth 1996, 161, 190-194.

(49) Liao, Z.-M.; Liu, K.-J.; Zhang, J.-M.; Xu, J.; Yu, D.-P. Phys. Lett. A 2007, 367, 207-210.

(50) Liao, Z.-M.; Hou, C.; Zhou, Y.-B.; Xu, J.; Zhang, J.-M.; Yu, D.-P. J. Chem. Phys. 2009, 130, 084708.

(51) Prades, J. D.; Hernandez-Ramirez, F.; Jimenez-Diaz, R.; Manzanares, M.; Andreu, T.; Cirera, A.; Romano-Rodriguez, A.; Morante, J. R. Nanotechnology 2008, 19, 465501.

(52) Mora-Seró, I.; Fabregat-Santiago, F.; Denier, B.; Bisquert, J.; Tena-Zaera, R.; Elias, J.; Lévy-Clément, C. Appl. Phys. Lett. 2006, 89, 203117.

(53) Bradley, R. K.; Arthur, B. E. J. Am. Chem. Soc. 1980, 30, 968980.

(54) Petermann, G.; Tributsch, H.; Bogomolni, R. J. Chem. Phys. 1972, 57, 1026-1032.

(55) Noguchi, H.; Kondo, T.; Uosaki, K. J. Phys. Chem. B 1997, 101, 4978-4981.

(56) Williams, R. J. Chem. Phys. 1960, 32, 1505-1514.

(57) Gerischer, H. J. Electrochem. Soc. 1966, 113, 1174-1182.

(58) Djurišić, A. B.; Ng, A. M. C.; Chen, X. Y. Prog. Quant. Electron. 2010, 34, 191-259.

(59) Liu, X.; Wu, X. H.; Cao, H.; Chang, R. P. H. J. Appl. Phys. 2004, 95, 3141-3147.

(60) Sun, Y.; George Ndifor-Angwafor, N.; Jason Riley, D.; Ashfold Michael, N. R. Chem. Phys. Lett. 2006, 431, 352-357.

(61) Fichou, D.; Kossanyi, J. J. Electrochem. Soc. 1986, 133, 16071617. 